\title{
Study on Seismic Resistance of Civil Engineering Structure Design
}

\author{
Lihui Shi ${ }^{1}$ \\ Xijing University, Xi'an, 710123, China \\ E-mail: 494625508@qq.com
}

\author{
Xiaofang $\mathrm{Li}^{2}$ \\ Xijing University, Xi'an, 710123, China \\ E-mail: lixiaofangxijing@126.com
}

\begin{abstract}
In order to further improve the seismic performance and stability of civil engineering, as much as possible to reduce the economic losses caused by the earthquake, so, improve the structure of civil engineering structure seismic capacity should be further researched by relevant staff. Based on the actual situation of civil engineering construction, this paper analyzes and discusses the factors affecting the seismic performance, and puts forward some suggestions for the design of civil engineering structures, which provide reference for the design of civil engineering structures in the future.
\end{abstract}

Keywords-Civil Engineering; Structural Design; Seismic Technology; Seismic Measures

\section{INTRODUCTION}

With the continuous development of social economy and the acceleration of urbanization, the construction of civil engineering has made rapid development, which has positive significance to improve the living standards and quality of life of the people. In order to guarantee the construction of civil engineering can play its biggest role, structure design is very important. In the whole design of civil engineering, to make the whole project with security and stability, we must consider the seismic performance of the whole project, and take the corresponding measures to improve the seismic performance of engineering construction. In civil engineering design process, due to the engineering design technology, design system, design personnel and other factors, there will be no full consideration of the problem of the seismic performance of the whole structure, which often causes adverse effects on the whole project, even buried security risks. In the future development of civil engineering, it should correctly understand the problems in the seismic design and construction, and actively take measures to improve the structure of seismic resistance, so that ensure the quality of the whole civil engineering.

\section{ANALYSIS OF FACTORS AFFECTING THE SEISMIC PERFORMANCE OF CIVIL ENGINEERING STRUCTURES}

In civil engineering construction, the seismic performance is one of the important factors. In order to improve the seismic performance of the whole project, first of all, it's good to understand the influence factors of seismic performance. In the design of civil engineering structures, we should base on the specific circumstances of the construction site and then combined with these factors into the design; only in this way can we achieve the best design results.

\section{A. Site Selection for Civil Engineering Construction}

In the design of civil engineering structures, the direct impact on the seismic performance of the whole building is the selection of the construction site. In order to improve the seismic performance of the building, we should choose a good site, which can bring convenience to people's life in the future. In the selection of the site, we should pay attention to the site of the foundation, the ground state of the structure has an important impact on the seismic performance of the entire structure, once the earthquake occurs, the stable foundation of the engineering structure suffered little damage than ground of an unstable foundation. In general, in the site for construction we should choose flat open and hard geological site geology or dense and uniform in the hard soil for site design and construction, in order to avoid landslide, fault, depression and poor condition of terrain and geology, ensure the foundation stability, essentially improve the civil engineering structure seismic performance.

\section{B. Selection of Materials and Design of Mechanism}

In the design of civil engineering structures, we can select the appropriate structural system and materials. Most of civil engineering construction is constructed in the form of reinforced concrete structure, but the reinforced concrete itself is easy to deformation, bending and lateral displacement, so the design should be carried out in all directions. To improve the seismic performance of the structure we can use steel pipe concrete structure, steel reinforced concrete structure, steel structure and so on, replacing the reinforced concrete, so can effectively reduce the size of the column section, to optimize the seismic performance of the overall objectives.

\section{Reasonable control of civil engineering structure}

Whatever form of engineering structures need to have the appropriate height, the choice of the appropriate structure height has a very important significance for the improvement of seismic performance. From the practical experience, when the earthquake occurs, the damage suffered by the small height of the structure is relatively small, the structure is high, the structure is easy to deformation, the seismic performance is poor, and the damage is more serious. Therefore, in the design of civil engineering structures, we should consider the factors of the structure height; only the right and reasonable structure can improve the seismic force of the whole building. 


\section{Seismic Intensity of Structure}

At present the relevant standard requirements of our country to the seismic resistance of civil engineering structure is low, especially in the axial compression ratio, reinforcement ratio, Bearing capacity of beams and so on. So in the design seismic resistant intensity is considered, in structural design generally follow the basic principle of "no damage in small earthquake, middle earthquake can repair, severe earthquake does not fall", at the same time to do a good job in the seismic intensity of the audit work, in order to improve the seismic behavior of the whole project.

\section{DESIGN MEASURES FOR EARTHQUAKE RESISTANT DESIGN OF CIVIL ENGINEERING STRUCTURES}

\section{A. Pay Attention to Site Selection}

In the selection of the structure of the site, firstly we should do a good job in the investigation and reconnaissance, the local terrain and geological conditions should be fully mastered, on the basis of which to make the selection of appropriate seismic site. For fault, landslide, depression and other bad areas, we should keep away from them reasonable, so as to ensure the overall seismic performance of civil engineering structure. As to the locations can't be avoid, in order to improve the overall seismic performance of the structure, only to take the corresponding strengthening measures, strengthen the treatment on the bad site, on the one hand to meet the requirements of construction, on the other hand to enhance the seismic performance of the structure.

\section{B. Reasonable Selection of Engineering Materials}

Reasonable selection of building materials is one of the important measures to improve the seismic performance of the whole civil engineering structure. In the beginning, according to the parameters of various materials we analyze its seismic performance, it is important to pay attention to the variation of the material parameters, which should becarefully studied and analyzed. At the same time, the damage of a few materials will not affect the seismic performance of the whole structure. Popular speak even a few components can not run normally, but doesn't affect other components, to avoid the phenomenon of excessive reliance on one component of.

For the civil engineering structural system, we must first have a clear calculation sketch, and the structure should have well anti deformation capacity, bearing capacity and the ability of seismic energy consumption. So in the general construction we select reinforced concrete for structure construction, but the structural system also must have a reasonable strength and rigidity, the possible existence of weak links to take effective measures, in order to ensure the seismic performance of the whole structure.

\section{Reinforced Seismic Performance of Reinforced Beam Column Joints}

In the design of civil engineering structures, the seismic design should ensure that the structure is uniform, and ensure the stability and uniformity of the whole structure. In order to improve the seismic performance of the whole engineering structure, we should consider all aspects of the design, and ensure that each member has a good ductility, at the same time to increase the shear resistance of the various components; the plastic deformation structure should be reasonable choice.

We should improve the seismic performance of reinforced concrete at the design of the seismic performance of beam column joints, and the bearing capacity and ductility are improved at the same time. The practical operation method is that the design of the related principle of strong column weak beam, strong shear weak bending, strong node weak component, appropriate control column's axial compression ratio and column section size, improve the structure of the joints, in order to improve the seismic capacity of the joints.

\section{The Seismic Performance of the Structure with Multi - channel Seismic Defense Line is Provided.}

The setting of multi-channel line of defense is essential to ensure the seismic performance of the whole structure. The design principle of multi defense line is that in the event of an earthquake, the first is a good ductility of the member to play its seismic role, other components also play a role but the impact is small. In the actual process, only the first line of defense appears the first yield will other lines play a role. Therefore, in the design, to set up the defense, in order to ensure the seismic performance of the whole structure.

\section{CONCLUSION}

In civil engineering structure design, the design of seismic performance is very important, so it should be integrated in the design of seismic design. In order to improve the seismic performance of the structure, it should be concluded that the above mentioned measures should be strengthened, and the professional quality of the design staff should be improved, so as to improve the seismic performance of civil engineering structures. 
Figures and Tables

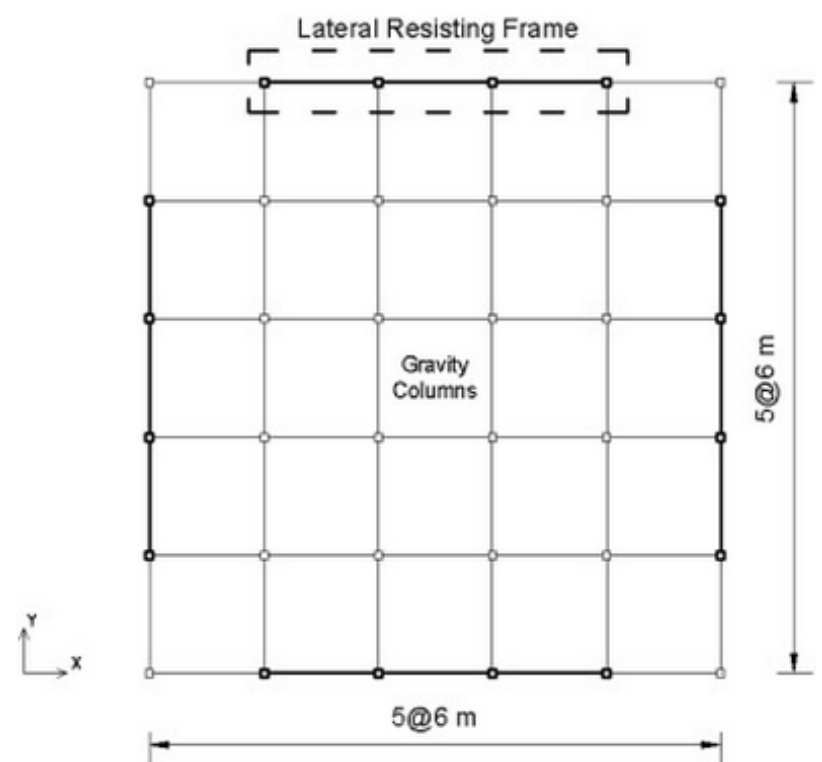

Figure 1. Floor Plan Showing Layout of Lateral and Gravity Load Resisting Frames of Office Building Structure.

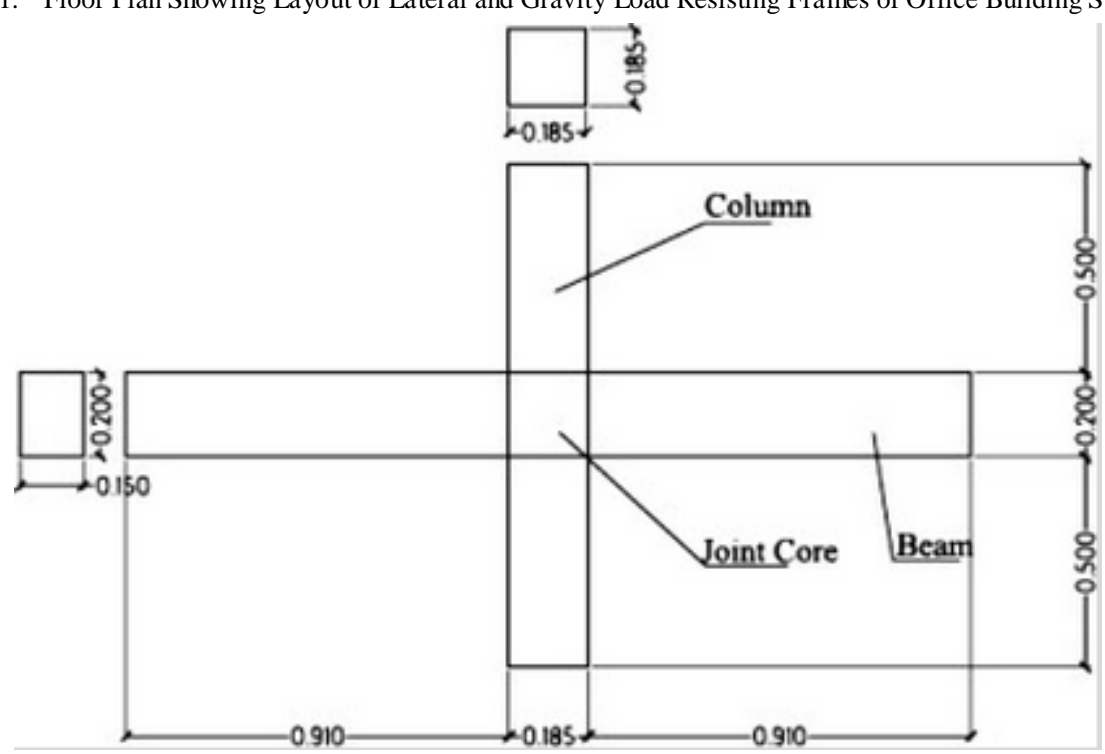

Figure 2. Beam-column Connection Details (units: m)

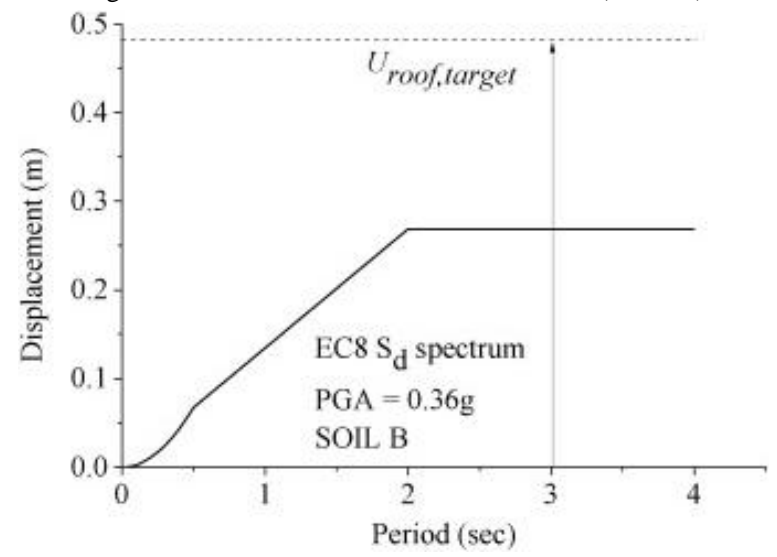

Figure 3. Displacement Design Spectrum of Frame for PGA $=0.36 \mathrm{~g}$ and Soil Class B 


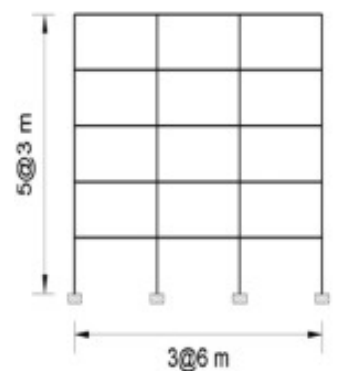

(a)

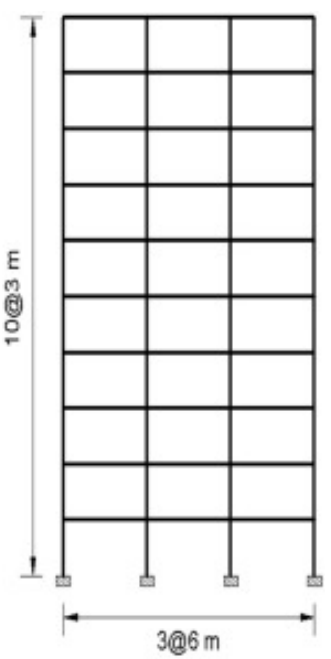

(b)

Figure 4. Lateral Resisting Frames (a) with Five Stories and (b) with Ten Stories

\section{REFERENCES}

[1] Y. Bozorgnia, V.V. Bertero.Earthquake Engineering: From Engineering Seismology to Performance-Based Engineering.CRC Press, Boca Raton, Florida (2004)

[2] Eurocode 8, EC8.Design of structures for earthquake resistance, part 1: general rules, seismic actions and rules for buildings.European Standard EN 1998-1, Stage 51 Draft, European Committee for Standardization (CEN), Brussels (2004)

[3] P. Fajfar.A nonlinear analysis method for performance based seismic design.Earthquake Spectra, 16 (3) (2000), pp. 573-592

[4] M.J.N. Priestley, G.M. Calvi, M.J. Kowalsky.Direct DisplacementBased Seismic Design.IUSS Press, Pavia, Italy (2007)

[5] T.J. Sullivan, M.J.N. Priestley, G.M. Calvi.Direct displacementbased design of frame-wall structures.J. Earthq. Eng., 1 (2006), pp. 91-124
[6] L. Macedo, J.M. Castro.Direct displacement-based seismic design of steel moment frames.Proceedings of 15th World Conference on Earthquake Engineering, Lisbon, Portugal (September 24-28, 2012)

[7] G.S. Kamaris, G.D. Hatzigeorgiou, D.E. Beskos.A new damage index for plane steel frames exhibiting strength and stiffness degradation under seismic motion.Eng. Struct., 46 (2013), pp. 727736

[8] K. Kawashima, K. Aizawa.Earthquake response spectra taking account of number of response cycles.Earthq. Eng. Struct. Dyn., 14 (1986), pp. 185-197

[9] A.K. Tiwari, V.K. Gupta.Scaling of ductility and damage-based strength reduction factors for horizontal motions.Earthq. Eng. Struct. Dyn., 29 (2000), pp. 969-987

[10] S.K. Kunnath, Y.H. Chai.Cumulative damage-based inelastic cyclic demand spectrum.Earthq. Eng. Struct. Dyn., 33 (2004), pp. 499-520 